\title{
VIVIENDA Y URBANIZACIÓN EN LA CIUDAD DE ARICA: COSTA, DESIERTO E INTEGRACIÓN SUBSIDIARIA EN LA FRONTERA NORTE DE CHILE (2000-2019)*
}

\author{
HOUSING AND URBANIZATION IN THE CITY OF ARICA: \\ DESERT AND SUBSIDIARY INTEGRATION ON THE NORTH BORDER \\ OF CHILE (2000-2019)
}

\author{
Rodrigo Hidalgo Dattwyler ${ }^{* *}$, Miguel González Rodríguez ${ }^{* *}$, Carlos Vergara Constela*** \\ $y$ Voltaire Alvarado Peterson ${ }^{* * * * *}$
}

\begin{abstract}
Se analiza la producción habitacional de vivienda subsidiada en la ciudad de Arica, Chile. Mediante un enfoque metodológico mixto, que combina técnicas estadísticas, móviles y orales, se discuten las retóricas gubernamentales de la integración social urbana en la vivienda subsidiada. Los resultados nos muestran que la vivienda social en Arica ha redefinido las periferias norte y sur de la ciudad. La evaluación en torno a los mismos criterios urbanos que fundamentan la política nos permite interpretar que la producción de vivienda social adquiere la forma de una precariópolis estatal, signada por la densificación periférica, espacios monofuncionales, aislado del equipamiento de la ciudad consolidada y fragmentación a escala barrial.
\end{abstract}

Palabras claves: Vivienda social, integración social urbana, sostenibilidad, precariópolis, Arica.

The production of subsidized housing in the city of Arica, Chile is analyzed. Through a mixed methodological approach, combining statistical, mobile and oral techniques, government rhetoric of urban social integration in subsidized housing is discussed. The results show us that social housing in Arica has redefined the northern and southern peripheries of the city. The evaluation around the same urban criteria that underpin the policy allows us to interpret that the production of social housing takes the form of a state precariopolis, marked by peripheral densification, monofunctional spaces, isolated from the equipment of the consolidated city and fragmentation at neighborhood scale.

Key words: Social housing, urban social integration, sustainability, precariopolis, Arica.

\section{Introducción}

La vivienda social ha sido un fenómeno central en la producción del espacio urbano de las ciudades chilenas. Su trayectoria histórica la señala como objeto de luchas y demandas, con mayor protagonismo desde inicios del siglo XX hasta la actualidad. Es en esta última etapa que se instala una política habitacional subsidiaria vertebral para el neoliberalismo dictatorial (1973-1990), que posteriormente es ajustado durante el primer decenio presidencial democrático (Haramoto et al. 1987; Tapia 2011; Navarrete y Toro 2019). Las cifras entre 1990 y 2000, descritas como exitosas, se diluyeron entre el colapso de las unidades habitacionales por la exigua calidad de su construcción y una evidente segregación y lejanía disfuncional de los centros urbanos (Oezler 2012; Sabatini y Salcedo 2007).

El nuevo siglo se inicia con la sofisticación del neoliberalismo subsidiario, basado en que la marginalidad urbana debía desarmarse con el paradigma de la integración social y territorial, centrado en la calidad de las viviendas y la producción de óptimas condiciones de entorno residencial. Esta sofisticación se aprecia en el aumento de los programas estatales multisectoriales dirigidos al mejoramiento de las viviendas ya construidas, su entorno, equipamiento comunitario e infraestructura, además de su incorporación a las nuevas edificaciones (Hidalgo et al. 2016; Alvarado, 2019). Estas discusiones son la base de la actual Política Nacional de Desarrollo Urbano -PNDU- que, entre sus fundamentos,

\footnotetext{
* $\quad$ Esta investigación se enmarca en el proyecto FONDECYT Regular 1191555 "La producción de vivienda subsidiada en ciudades fluviales, marinas y lacustres en Chile: integración y sostenibilidad 2000-2017".

** Instituto de Geografía, Pontificia Universidad Católica de Chile. Santiago, Chile. Correo electrónico: rhidalgd@uc.cl

** Instituto de Geografía, Pontificia Universidad Católica de Chile. Santiago, Chile. Correo electrónico: mgonzalezro.fe@ gmail.com

*** Instituto de Geografía, Pontificia Universidad Católica de Chile. Santiago, Chile. Correo electrónico: cdvc87@gmail.com

*****Departamento de Geografía, Universidad de Concepción, Concepción, Chile. Correo electrónico: voalvarado@udec.cl
} 
coloca a la gestión de ciudades sostenibles como una orientación multidimensional respecto de la justicia, la integración, las áreas verdes, el acceso a salud y educación, transporte y servicios en general (PNDU, 2014).

Por consiguiente, este estudio se enfoca en la observación, descripción y análisis de la política de vivienda social y la urbanización reciente en la ciudad de Arica. Esta observación permitirá registrar el proceso de emplazamiento de los conjuntos habitacionales y los alcances socioespaciales de los discursos de integración que el Estado de Chile ha promovido en la Política Nacional de Desarrollo Urbano desde el 2014. En este sentido, el objetivo de esta investigación espera observar el desarrollo de la política de vivienda social y la urbanización en la ciudad de Arica en el ciclo neoliberal de las dos primeras décadas del siglo XXI.

El problema es que los ejercicios investigativos han estado centrados en las grandes ciudades y áreas metropolitanas, sin atender mayormente los impactos espaciales de las políticas de vivienda en ciudades medias (Pérez e Hidalgo, 2010; Valdebenito, 2014). Por su parte, los estudios acerca de la vivienda social situados en ciudades medias revelan excepcionalidades más allá de la escala y demografía, siendo fundamentales para conocer realidades urbanas (Vergara et al. 2015; Rojo et al. 2019; Orellana et al. 2016).

Así, el trabajo se organiza con la contextualización de la política subsidiaria de vivienda, enlazándose con los aspectos conceptuales de integración declarados en la PNDU. Posteriormente, se describe la producción habitacional en el espacio urbano de la ciudad de Arica, focalizándose en la integración social y territorial establecida por la PNDU y sus indicadores y, finalmente, se discuten los alcances de estas acciones analizando algunos de los resultados de su establecimiento en zonas urbanas que dan forma a una nueva dimensión de las precariópolis estatales, en la frontera norte de Chile.

\section{Metodología}

El procesamiento de los datos levantados contempló la aplicación de técnicas cuantitativas y cualitativas. Se utilizaron los Censos de Población y Vivienda correspondientes a 1982, 1992, 2002 y 2017 permitiendo el análisis intercensal y distribución espacial a partir de distritos censales y la agrupación de estos en zonas. Además, mediante solicitudes de acceso a la información pública, se requirió a la Seremi de Vivienda y Urbanismo de la Región de Arica y Parinacota una base de datos acerca de vivienda subsidiada para la zona urbana de Arica contemplando las unidades de vivienda producidas por año, cantidad de beneficiarios y tipos de subsidios. Lo anterior permitió tener un panorama general de la vivienda social, principalmente la distribución de variables, el cruce de algunas de ellas y la construcción de un índice de Duncan para analizar las dinámicas de segregación socioespacial. La aplicación del índice de disimilitud de Duncan,

Tabla 1. Técnicas de producción de datos

\begin{tabular}{|c|c|c|c|}
\hline Herramienta & Variable & Fuente & Producto \\
\hline \multirow[t]{4}{*}{ Estadística } & $\begin{array}{l}\text { Cantidad de viviendas } \\
\text { subsidiadas }\end{array}$ & $\begin{array}{l}\text { Seremi de Vivienda Región de Arica } \\
\text { y Parinacota }\end{array}$ & $\begin{array}{l}\text { Tabla con cantidades y porcen- } \\
\text { tajes según periodo (1980-2016) }\end{array}$ \\
\hline & Cantidad de vivienda según tipo & Censos de población y vivienda & $\begin{array}{l}\text { Tabla con cantidades según } \\
\text { periodo }(1982-2017)\end{array}$ \\
\hline & Población según zona & Censos de población y vivienda & $\begin{array}{l}\text { Tabla con cantidades según } \\
\text { periodo (1982-2017) }\end{array}$ \\
\hline & Segregación & Censos de población y vivienda & $\begin{array}{l}\text { Îndice de Duncan según trabajo } \\
\text { y educación. }\end{array}$ \\
\hline Observación & $\begin{array}{l}\text { Emplazamiento } \\
\text { Flujos } \\
\text { Equipamientos } \\
\text { Servicios } \\
\text { Paisaje } \\
\text { Relatos }\end{array}$ & $\begin{array}{l}\text { Realización de recorridos en terreno } \\
\text { en conjunto con un informante } \\
\text { clave, donde se identificaron } \\
\text { comercios, equipamientos, servicios y } \\
\text { características paisajísticas generales } \\
\text { de los barrios visitados, acompañados } \\
\text { del relato del informante y } \\
\text { conversaciones informales. }\end{array}$ & $\begin{array}{l}\text { Descripción general de barrios } \\
\text { de Arica donde la política de } \\
\text { vivienda subsidiada se ha loca- } \\
\text { lizado. Registro realizado con } \\
\text { fotografías y notas de campo. }\end{array}$ \\
\hline
\end{tabular}

Fuente: Elaboración propia. 
usualmente ocupado para revisar la homogeneidad de una población, permite ver qué tan dispersas se encuentran algunas variables frecuentemente usadas en los análisis urbanos de segregación (Rodríguez y Arriagada 2004). Estas variables, con las que podemos aproximarnos hacia el estudio de la desigualdad socioespacial, resultan claves para observar algunas formas de mixtura social (Kaztman 2001).

Las observaciones de campo se organizaron con técnicas cualitativas acompañadas por un informante clave residente en la ciudad, siendo clave para transitar por los nuevos espacios construidos. El sentido de las observaciones fue registrar y describir las centralidades, vialidades, paisajes, objetos, flujos, accesibilidad y amenidades, localizaciones de bienes y servicios en cada uno de los espacios de Arica más allá de la presencia de vivienda subsidiada, construyéndose un registro fotográfico. Estos datos fueron sometidos a un análisis de contenido cualitativo, tensionándose los valores estadísticos que miden la integración de estos conjuntos habitacionales. De esta forma, el análisis de política de vivienda subsidiada y del proceso de urbanización que la acompaña es abordado desde la estructura general que otorgan los datos oficiales y desde las posibilidades de carácter urbano que entregan estos espacios, asumiendo una perspectiva de carácter etnográfico.

\section{Más subsidios para la ciudad: historia reciente de las políticas de vivienda en el contexto neoliberal chileno}

Como se plantea al inicio del manuscrito, la política de vivienda social en Chile se ha sofisticado en el tiempo a partir del reconocimiento de sus propias limitaciones, las que han sido evidenciadas en el examen que la PNDU realiza en su texto (PNDU, 2014). Esto no quita que los objetivos del Ministerio de Vivienda y Urbanismo permanezcan en la línea de la eficiencia económica y de resguardo de los equilibrios fiscales, propia de los ajustes al modelo neoliberal imperante desde el régimen militar (Hidalgo, 2005). Por sobre la inversión pública, emerge la resignificación de la vivienda social hacia otra, ahora denominada subsidiada, con énfasis en las clases trabajadoras urbanas, calificadas "emergentes" en los distintos subsidios habitacionales vigentes (PNDU, 2014).

Para Fuster (2019), el neoliberalismo en las políticas de vivienda se diferencia en dos períodos.
El primero como un neoliberalismo fundacional, que refleja la continuidad entre la dictadura militar y los primeros gobiernos de la Concertación de Partidos por la Democracia liderados por la Democracia Cristiana (1990-2000). Este período, destaca Fuster (2019), se caracteriza por la ampliación y probable estructuración de un mercado de suelos orientado a la inversión y operación inmobiliarias, fortaleciendo el rol de la vivienda como eje en la construcción patrimonial de las familias chilenas de las clases más desposeídas y emergentes. Con la creación de la Región de Arica y Parinacota en 2008 se verifican 8.480 subsidios habitacionales hasta 2019, destinados a viviendas urbanas en modalidad de compraventa o autoconstrucción bajo comité de vivienda, con el objetivo de disminuir el déficit habitacional (MINVU, 2020).

El segundo período que define la autora se enmarca entre el inicio de los gobiernos de Ricardo Lagos (2000-2006) y Michelle Bachelet (2006-2010 y 2014-2018) y las presidencias de los partidos de derecha liderados por Sebastián Piñera (2010-2014 y 2018 a la fecha). Fuster (2019) llama a esto neoliberalismo híbrido, debido a la flexibilidad e innovación de las políticas de producción habitacional. A la continuidad del modelo subsidiario individual, se incorporan variables sociales y criterios territoriales que definen una política específica.

Una visión similar tiene Alvarado (2019), a partir del concepto de Estado Neoliberal de Bienestar. Pudiendo resultar un oxímoron epistemológico, se fundamenta en que uno de los pilares del modelo neoliberal chileno está en la defensa y promoción del derecho a la propiedad y la libre elección subsidiaria multisectorial. De esta manera, la construcción espacial de la ideología neoliberal establecería una estructura societaria originada en los procesos urbanos de subsidiarización, donde la política habitacional se erige como la principal productora de la propiedad residencial. Esta propuesta se entronca con la del neoliberalismo híbrido en que buscan comprender los diseños vinculados a una batería de subsidiaria focalizada en programas territoriales, como Chile Solidario (2004) y Chile Crece Contigo (2006), ambos hitos en el nuevo orden espacial donde el subsidio opera en tanto matriz reparadora ante los municipios más expoliados de los derechos que, de cierta manera, edifican el bienestar urbano y social (Galasso 2011; Fuster 2019; Alvarado, 2019). Entendiendo que estas bases rectificadoras 
impactan en las demandas locales, sus efectos políticos derivan en la creación de nuevos municipios, particularmente de ciudades medias o periferias metropolitanas, como es el caso de Hualpén en el Gran Concepción (Salinas y Pérez 2011).

\section{Ciudades integradas y sostenibles en la política de vivienda: elementos para el debate conceptual y aplicado en Chile}

El concepto de integración se entiende a partir del acceso a bienes y servicios con vínculo público -salud, educación en relación con la vivienda-que tienden a morigerar la segregación territorial urbana y potenciar las infraestructuras, fundamentalmente en transporte y comunicaciones, además de propiciar el encuentro social en el espacio habitado, entre otros aspectos (PNDU, 2014).

Con el inicio del período de alternancia entre Bachelet y Piñera (2010 a la fecha), el modelo de fomento habitacional se sofisticará introduciendo nuevos programas estatales, robusteciendo la construcción de significados respecto de la propiedad y la libre elección. El Sistema Integrado de Subsidios Habitacionales para grupos emergentes y clase media en 2011 (DS 1); y el Programa de Integración Social y Territorial de 2014 (DS 19) operan en tanto coadyuvantes a la rectificación integradora del modelo subsidiario residencial. Ambos programas destacan la hibridez excepcional en el enfoque bienestar, pues establece los límites normativos de los grupos sociales emergentes y define la extinción de la pobreza a partir del acceso a la vivienda. El significado de vulnerabilidad se agotaría con el ingreso a la dimensión urbana de la vida cotidiana de los grupos sociales excluidos.

Esta dimensión representacional del significado de la integración territorial se inscribe en el proyecto del Estado Neoliberal de Bienestar que señala Alvarado (2019). Siguiendo la regla de ahorro+hipoteca+subsidio, programas como el DS 19 instalan al Estado en principal posición frente al proceso urbano, esencial en la orientación neoliberal de la dictadura basado en la competencia por el mérito para una ciudadanía vulnerable (Salcedo 2010). En la cuestión de los significados esto último es relevante, debido a que las políticas de integración y mixtura social buscan que las familias menos favorecidas tengan posibilidades de mejorar sus condiciones y proyecciones a partir de la hipótesis del contacto entre grupos diferenciados, en este caso y como los estatuye la norma, de ciudadanías vulnerables y emergentes.

Asimismo, la concepción de integración en la PNDU está asociada a la (in)equidad en el acceso a bienes públicos y servicios urbanos (Ruiz-Tagle y Romano 2019). Esa visión ha dominado buena parte de los estudios urbanos chilenos, sosteniendo que el retroceso de la segregación significa un mejoramiento de las condiciones de integración de los habitantes en una lógica poligonal y topológica (Rodríguez y Arriagada 2004; Cáceres y Sabatini 2007; Arriagada y Morales 2006; Sabatini y Brain 2008). Sin embargo, resulta determinante el sesgo clasista existente en estos estudios. Los énfasis han estado puestos en la segregación de las periferias populares, analizadas desde la carencia material y procesos de guetización variados en intensidad o incapaces de transformar su espacio (Sabatini y Brain 2008; Ruiz-Tagle 2016). De esta manera, los aportes para la formulación de políticas públicas pasan por fomentar la mixtura social, lo que se traduce en que habitantes de clase media puedan localizarse en barrios populares mediante la compraventa de nuevas viviendas vinculadas a proyectos inmobiliarios. Pero si comprendemos que las movilizaciones de octubre de 2019 están basadas en un agotamiento o fractura de esta forma de integración (Mayol 2019), podemos entender que esta política pública ha sido insuficiente y desajustada a la complejidad social y cultural.

Si consideramos la integración social urbana como un asunto tanto funcional, comunitario y simbólico (Vergara-Constela, 2013), podremos atestiguar su complejidad y las distintas formas que puede engendrar en la vida cotidiana. La síntesis entre estos aspectos consideran el acceso a recursos pecuniarios, el establecimiento de redes de cooperación, reciprocidad y confianza, o la emergencia (o ausencia) de sentidos de pertenencia. Dichos aspectos pueden otorgar orientaciones más críticas para informar de los efectos urbanos de las políticas públicas que buscan mejorar la integración en la ciudad, más allá del establecimiento de fronteras simbólicas y físicas, duplicidad de instituciones e inaccesibilidad a su capital social.

\section{Vivienda subsidiada en el desierto fronterizo. Producción habitacional en la ciudad de Arica}

Los efectos de la condición fronteriza se constatan en la lejanía respecto del centro político del 
país. La creación de la Región de Arica y Parinacota en 2008 tuvo como intención disminuir los efectos sociales y políticos del abandono institucional que las regiones extremas representan frente al centralismo metropolitano ejercido desde Santiago, la capital de Chile. Esto se refleja en que uno de los hitos de la política urbana de la ciudad se enmarca en el período de crecimiento vía industrialización y modernismo urbano, entre 1953 y 1976, producido por medidas gubernamentales que buscaban incorporar al Departamento de Arica en el desarrollo productivo del país (Pizarro y Ríos, 2005; Calderón, 2014)

Arica promovió una propia descentralización administrativa a partir de la Junta de Adelanto de Arica (JAA) (1958-1976), generadora de cierta autonomía en la construcción de la ciudad desde una perspectiva local. Tras su desmantelamiento durante el régimen militar, la ciudad ha seguido un crecimiento del espacio urbano a partir de modelos estatales de producción habitacional homogénea (González y González 2019; Galdames y Ruz 2010; Galeno 2013).

Desde mediados de la década de 1950 la ciudad tuvo un importante período de urbanización desarrollista (1953-1976), seguido de otra etapa en que primó la desinversión y la consecuente relegación de la región por parte del Estado (Bustos, 2005). Sin embargo, desde el 2008 a la fecha se constata un incentivo basado en estrategias habitacionales, obras de mejoramiento urbano y de proyección regional, donde el rubro de la construcción es clave en la economía regional y comunal (Cavieres y Chávez, 2014).

En la década de los ochenta, la política habitacional trazó el nuevo frente de expansión de la ciudad hacia el nororiente de Arica, cruzando el río San José. Esta urbanización se instala en sectores colindantes a barrios industriales, caracterizados por la presencia de fábricas, distribución y bodegaje. Es en esta década donde, además, se levantan las poblaciones Tacora, Zapahuira, Guallatire, Ancolacane y el inicio del complejo habitacional Los Industriales. Son casas de 1 o 2 pisos cuyo tamaño va desde los 22 metros cuadrados, por ejemplo, en el conjunto Livircar; llegando hasta los 51 metros en el caso de viviendas pareadas (MINVU, 1998).

Para 1990, el foco de la producción habitacional manifiesta continuidades que el Estado Neoliberal de Bienestar y su perfeccionamiento normativo, a partir de los programas de Vivienda Básica y Vivienda Progresiva, a los que se agrega el Programa de Empleados y Trabajadores (PET). Son estos aportes fiscales los que promueven la edificación del emblemático proyecto de Cerro Chuño, localizado al nororiente de la Avenida Capitán Ávalos, corredor estructurante de la zona norte de la ciudad (Valdebenito y Navarro, 2019). Desde aquí se organiza el crecimiento de Arica hacia el suroriente, con la construcción del conjunto habitacional Nueva Esperanza, localizado en la entrada oriente del río San José a la ciudad, detonando una incipiente urbanización hacia el valle de Azapa. Hacia el sur, la proyección residencial de la ciudad se consolida con los conjuntos habitacionales Guañacagua y Tucapel. A finales de esta misma década se construirá también Chinchorro Oriente.

Los efectos en la trama urbana y sus modificaciones se explican por el crecimiento lineal de la ciudad, alcanzando las 1.600 hectáreas, dejando a la vivienda social proyectada hacia Las Laderas en Chinchorro Oriente y hacia el borde del cerro La Cruz (MINVU, 1998). La Figura 1 y la Tabla 2 describen estos roles, a propósito de la producción de vivienda social en el período 1980-2016, en el que se construyeron aproximadamente 20.000 unidades habitacionales, generando transformaciones en la morfología urbana de Arica. La diversidad en las tipologías residenciales se expresa en la caracterización de los períodos intercensales expresada en la Tabla 3.

Llegado el nuevo siglo se inicia la implementación de nuevos programas, como Construcción en Nuevos Terrenos y Construcción en Sitio Residente en donde se registra un aumento del tamaño de las unidades de vivienda, alcanzando un máximo de 60 metros cuadrados, a fines del período en estudio. Siguiendo los patrones de emplazamiento anteriormente descritos, la producción de vivienda social continúa su consolidación hacia el norte y sur de la ciudad. Hacia el primero, la urbanización avanza hacia el sector Chinchorro Oriente y hacia la playa Las Machas, mientras que, en el caso del segundo, continúa hacia el cerro La Cruz, en la zona denominada Pampa Nueva.

\section{Resultados espaciales: integración y segregación}

Estas evidencias permiten cuestionar los alcances del bienestar híbrido del espacio urbano relatado en las secciones anteriores. La década de 1990, definida por los ajustes y perfeccionamiento 


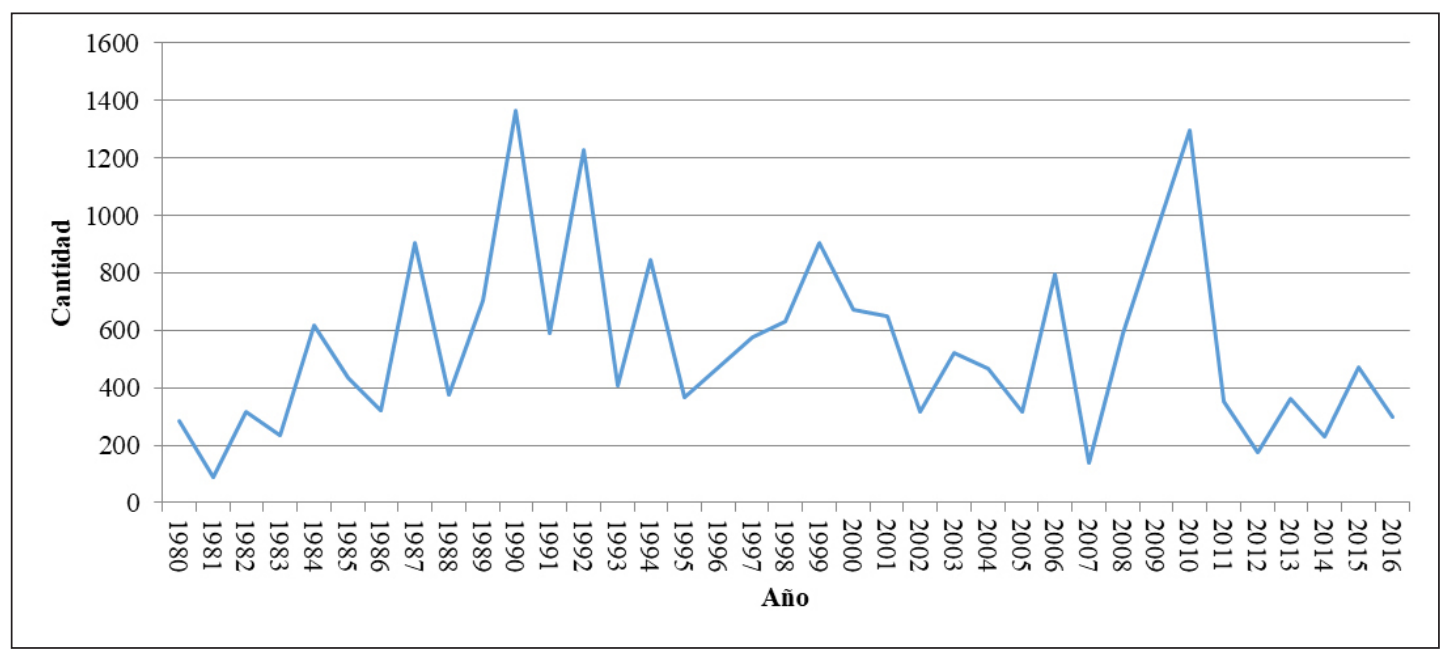

Figura 1. Viviendas sociales construidas en Arica (1980-2016).

Fuente: Elaboración propia a base de Seremi de Vivienda y Urbanismo, Región de Arica y Parinacota (2019).

Tabla 2. Cantidad de viviendas sociales construidas (1980-2016)

\begin{tabular}{lrrr}
\hline \multicolumn{1}{c}{ Período } & $\begin{array}{c}\mathrm{N}^{\mathbf{2}} \\
\text { Vivienda }\end{array}$ & \multicolumn{1}{c}{$\%$} & $\begin{array}{c}\% \\
\text { Acumulado }\end{array}$ \\
\hline $80-84$ & 1.544 & 7,61 & 7,61 \\
$85-89$ & 2.741 & 13,52 & 21,13 \\
$90-94$ & 4.438 & 21,89 & 43,02 \\
$95-99$ & 2.955 & 14,57 & 57,60 \\
$2000-2004$ & 2.626 & 12,95 & 70,55 \\
$2005-2009$ & 2.776 & 13,69 & 84,24 \\
$2010-2014$ & 2.423 & 11,95 & 96,19 \\
$2015-2016$ & 773 & 3,81 & 100,00 \\
\hline Total & 20.276 & 100,00 & \\
\hline
\end{tabular}

Fuente: Elaboración propia a base de la Seremi de Vivienda y Urbanismo, Región de Arica y Parinacota (2019).

en los programas de fomento a la vivienda; y una segunda etapa sustentada por la sofisticación en la gestión política advierten el aumento de las viviendas construidas entre períodos censales. Ejemplo de ello es que la tipología que registra mayor aumento es el departamento (período 2002-2017), coincidiendo con los modelos de condominio social de integración. Estas estrategias de verticalización subsidiaria se entroncan a las dinámicas de los desarrolladores privados, quienes finalmente construyen y comercializan su oferta basándose en la estructura normativa de los subsidios estatales. Además, a pesar de estos indicadores, en las últimas décadas no se atestigua una disminución significativa de la vivienda precaria.
La producción de vivienda subsidiada señala expansiones en la trama urbana hacia el norte y sur de Arica. En ambas zonas, las diferencias de la urbanización se estructuran según la cercanía a amenidades como los litorales marinos y fluviales, estos últimos próximos al valle de Azapa. A la vez, en la denominada punta norte se aprecia una segmentación entre costa y cerro. Cerca del mar se localiza la vivienda subsidiada focalizada en los grupos sociales emergentes, categorización un tanto oscura en términos jurídicos y territoriales al situarse en el inicio de las clases medias y por sobre los grupos vulnerables, que además define la densidad de las fronteras urbanas hacia las direcciones que señala Arica.

$\mathrm{Si}$ en el borde costero se erigen los barrios de las clases subsidiadas, en las faldas del cerro se emplazan las viviendas creadas en el marco de programas destinados para las clases populares. Por su parte, el sur se consolida como un espacio de producción intensiva de vivienda, denominado El Alto de Arica, en referencia a la explanada conurbada en La Paz, Bolivia. De manera más incipiente, estas formas de urbanización avanzan en conexión hacia San Miguel de Azapa, camino por donde se presentan parcelas de agrado y vivienda precaria en la cercanía al río.

Esta lógica en la distribución espacial de la vivienda subsidiaria permite cuestionar las consecuencias actuales respecto del avance de los paradigmas gubernamentales de la integración, cuyos efectos 
materiales estarían rompiendo o consolidando los patrones de segregación socioespacial para los que fueron diseñados. Las consecuencias pueden evaluarse conceptualmente, a partir de las mismas declaraciones normativas y prerrogativas contenidas en los documentos institucionales rectores de lo que los espacios urbanos deben ser.

Desde un enfoque cultural de la arquitectura de estas construcciones, González (2018) señala que las viviendas subsidiadas han asimilado y chilenizado el habitar de los aymaras urbanos, a modo de asimilación cultural desde el Estado (Díaz et al. 2014).
Para trabajar respecto de estas evidencias se debe considerar que la trayectoria temporal de los últimos cuarenta años describe un efecto centrífugo en la distribución de la población ariqueña. Las mayores concentraciones son advertidas en las zonas norte y sur, mientras que en las áreas centrales se aprecia un leve decrecimiento (Tabla 4), verificándose los efectos espaciales de los subsidios actuales.

En cuanto a la accesibilidad a servicios urbanos de primera necesidad, la cobertura a centros de salud primaria es deficiente en las zonas norte, sur y suroriente (Figura 2). Más compleja es la situación

Tabla 3. Tipos de vivienda (1982-2017)

\begin{tabular}{lrrrr}
\hline \multicolumn{1}{c}{ Tipo de vivienda } & 1982 & 1992 & 2002 & 2017 \\
\hline Casa & 23.953 & 30.755 & 41.868 & 55.557 \\
Departamento & 3.546 & 4.356 & 4.483 & 12.756 \\
Conventillo & 633 & 745 & 442 & 995 \\
Emergencia, mediagua, rancho o ruca & 5.464 & 4.908 & 2.897 & 2.350 \\
Vivienda tradicional indígena & & & 166 \\
Móvil & 8 & 9 & 34 & 45 \\
Otra particular & 86 & 62 & 406 & 545 \\
Vivienda colectiva (residencia, pensión, hotel, motel, internado, otras) & 212 & 210 & 241 & 225 \\
Viajeros / transeúnte & 1 & 1 & 7 & 1 \\
Operativo calle & & & & 1 \\
\hline Total & 33.903 & 41.046 & 50.378 & 72.641
\end{tabular}

Fuente: Elaboración propia a base de Censos de Población y Vivienda 1982, 1992, 2002 y 2017. Instituto Nacional de Estadísticas, Chile.

Tabla 4. Población según zona de la ciudad (1982-2017)

\begin{tabular}{|c|c|c|c|c|}
\hline Zona $^{\mathrm{a}}$ & 1982 & 1992 & 2002 & 2017 \\
\hline Puerto y Centro Histórico & 16.919 & 15.603 & 12.388 & 11.080 \\
\hline Junta de Adelanto & 27.317 & 24.090 & 20.241 & 19.579 \\
\hline Centro Río San José & 52.265 & 56.815 & 51.098 & 47.160 \\
\hline Norte Litoral $^{\mathrm{b}}$ & 28.172 & 44.795 & 12.816 & 20.728 \\
\hline Nororiente & 1.205 & 1.402 & 44.345 & 61.820 \\
\hline Sur "El Alto" & 14.795 & 15.158 & 28.432 & 36.971 \\
\hline San Miguel de Azapa & 5.750 & 10.989 & 14.991 & 21.601 \\
\hline Frontera & 590 & 594 & 649 & 478 \\
\hline
\end{tabular}

aLas zonas incorporadas en la Tabla 3 se realizaron mediante la agrupación de los siguientes distritos censales (en paréntesis): Puerto y Centro Histórico (Puerto, El Morro, Condell); Junta de Adelanto (José Miguel Carrera, Dittborn, Regimiento); Centro Río San José (San José, Población Chile, José Manuel Balmaceda, Parque Lauca, Las Torres); Norte litoral (Chinchorro); Nororiente (Pedro Blanquier, Cancha Rallada, Chacalluta); Sur "El Alto" (Fuerte Ciudadela, Chaca); San Miguel de Azapa (Azapa); Frontera (Molinos). bLa abrupta disminución de población de esta zona se explica por lo siguiente: en los censos de 1982 y 1992 el distrito Chinchorro abarcaba toda la zona norte no fronteriza de Arica. Para el 2002, este distrito fue dividido mediante la creación de los distritos Pedro Blanquier y Cancha Rallada, lo que implica que este distrito se vea con una disminución abrupta de población.

Fuente: Elaboración propia a base de Censos de Población y Vivienda 1982, 1992, 2002 y 2017. Instituto Nacional de Estadísticas (INE). 


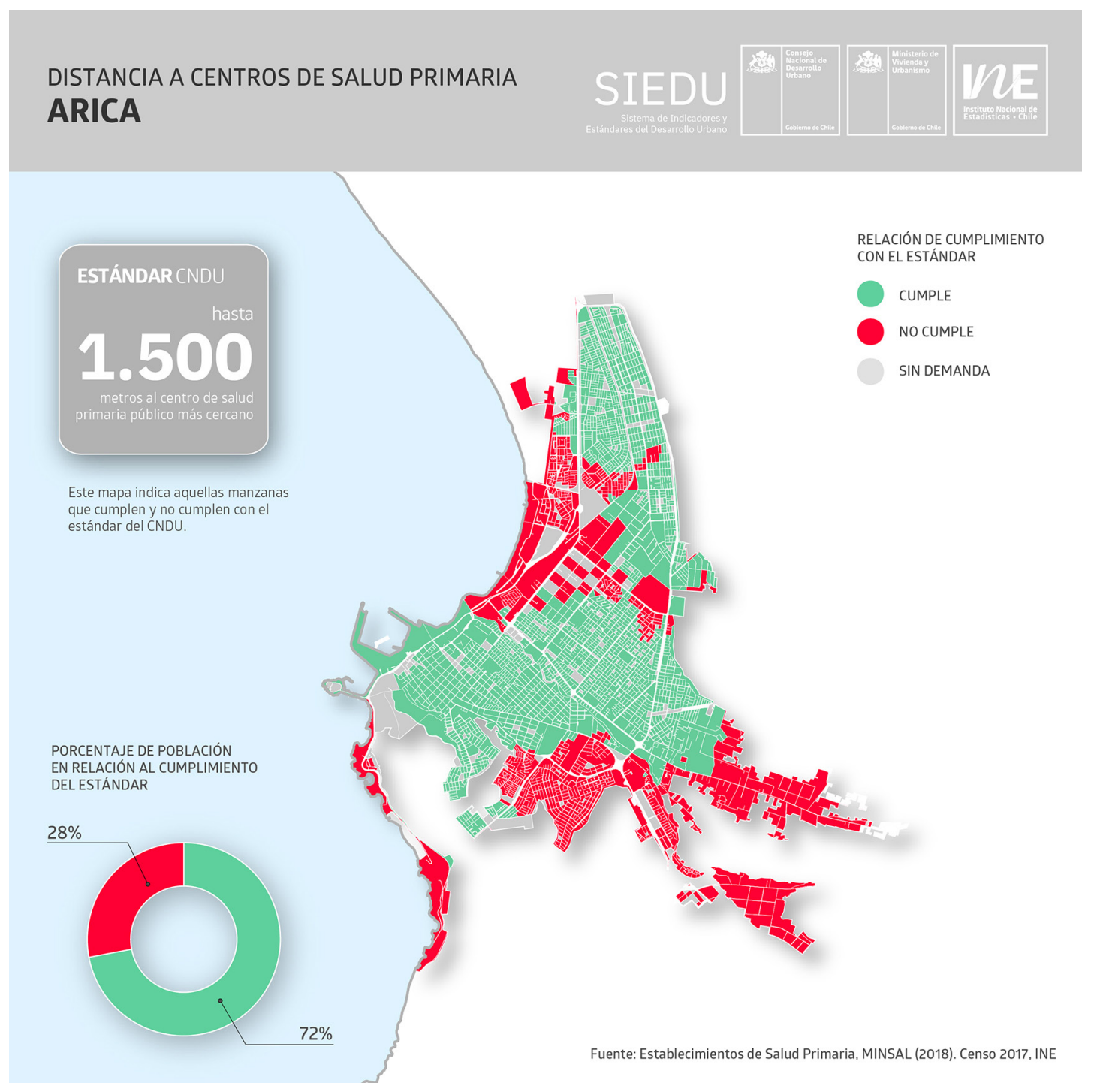

Figura 2. Distancia a centros de salud primaria. Distance to primary help centers.

Fuente: Sistema de Indicadores y Estándares del Desarrollo Urbano (SIEDU). Instituto Nacional de Estadísticas, Ministerio de Vivienda y Urbanismo, Consejo Nacional de Desarrollo Urbano y Programa Naciones Unidas para el Desarrollo, 2017.

de incumplimiento para los estándares de la PNDU (2500 metros en radio) respecto de la relación de proximidad entre establecimientos educacionales preescolares y viviendas subsidiadas (Figura 3); de hecho, solo algunos barrios centrales y nuevos conjuntos de vivienda subsidiada cumplen con el mencionado indicador.

La lectura de estas evidencias cartográficas devela que en la periferia de la ciudad se acumulan más desventajas, las que son visibles ante los indicadores de segregación trabajados, los que señalan un leve aumento en el grado de concentración de la población de jefes/as de hogar que poseen estudios superiores (desde técnico-profesional en adelante), como también las viviendas de mejor calidad (Tabla 5). Esto refleja que entre quienes poseen dichos atributos y quienes no opera una segregación más agresiva.

Este tipo de análisis estadístico configura ideas generales acerca de la estructura socioespacial de 


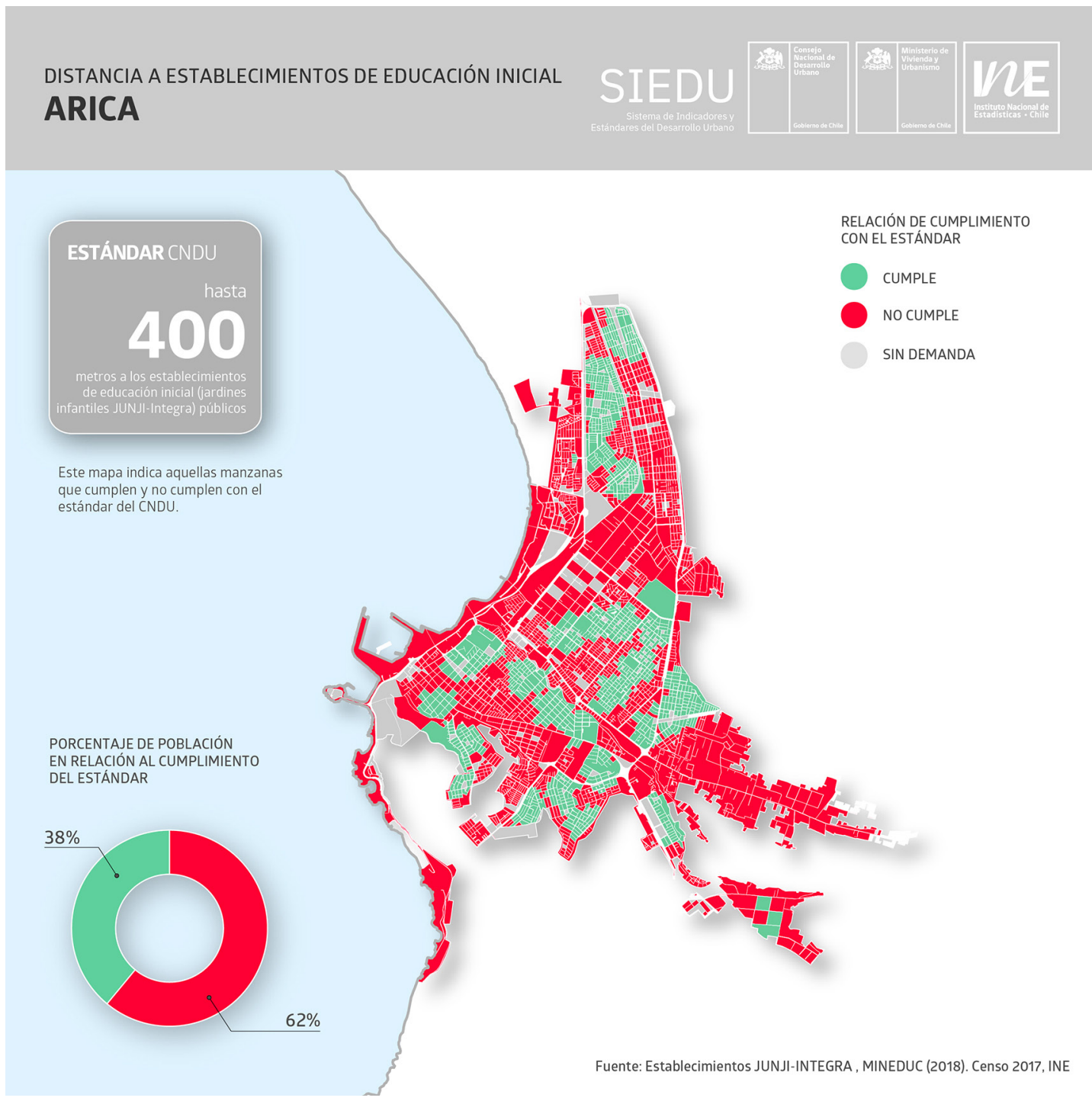

Figura 3. Distancia a establecimientos de educación inicial.

Fuente: Sistema de Indicadores y Estándares del Desarrollo Urbano (SIEDU). Instituto Nacional de Estadísticas, Ministerio de Vivienda y Urbanismo, Consejo Nacional de Desarrollo Urbano y Programa Naciones Unidas para el Desarrollo, 2017.

la ciudad acusando, a su vez, ciertas limitaciones geográficas. Entre ellas está el impedimento a una evaluación cualitativa del paisaje urbano resultante de estas políticas, sus fronteras y representaciones frente al litoral marino. Por lo mismo, la observación y el diálogo con informantes claves resultan imperiosos para indagar la estructura urbana.

\section{Los barrios subsidiados del desierto norte de Chile}

Siguiendo la concentración de conjuntos de vivienda subsidiada expuesta en las anteriores secciones, se organizó un recorrido basado en técnicas observacionales descriptivas del habitar y transitar cotidianos (Pellicer et al. 2013). El propósito estuvo en explorar las potencialidades analíticas de la producción de significados y problematizar datos cuantitativos expresados en tablas o cartografías a 
Tabla 5. Índice de Duncan. Datos generales acerca de segregación socioespacial en Arica 2002-2017

\begin{tabular}{lccc}
\hline \multicolumn{1}{c}{ Variable } & 2002 & 2017 & Dif. \\
\hline $\begin{array}{l}\text { Jóvenes que no estudian } \\
\text { ni trabajan }\end{array}$ & 0,153 & 0,103 & $-0,05$ \\
$\begin{array}{l}\text { Población con estudios } \\
\quad \text { superiores }\end{array}$ & 0,189 & 0,241 & 0,0518 \\
$\begin{array}{l}\text { Calidad de la pared } \\
\text { Calidad del techo }\end{array}$ & 0,372 & 0,416 & 0,0442 \\
Calidad del piso & 0,216 & 0,317 & 0,1013 \\
\hline
\end{tabular}

Fuente: Elaboración propia a base de Censos de Población y Vivienda 2002 y 2017. Instituto Nacional de Estadísticas (INE).

partir de las tramas estructurantes de los usos del suelo y sus condicionantes en relación con la forma en que se habita el espacio urbano ariqueño. La toponima de las imágenes se presenta en la Figura 4.

\section{Arica Norte}

La más importante ruta en la zona norte de Arica es la Avenida Santa María. El ingreso a esta zona está definido por un centro comercial integrador de múltiples servicios que, a su vez, segmenta el sector norte en dos partes: una litoral y otro nororiente.
Hacia la línea de costa es posible apreciar nuevos espacios residenciales focalizados en condominios ajenos a la oferta subsidiaria.

Por esta ruta se ingresa al barrio Santa María, emplazado en la anterior zona industrial de Arica. En la actualidad está compuesto por terrenos amplios donde aún persisten actividades de bodegaje y logística, las que conviven con nuevos usos comerciales, como ferreterías y los denominados mall chinos. La conversación al paso devela un proceso de largo aliento, iniciado a mediados de la década de 1970 en que se suceden períodos de abandono en la zona. Los usos mixtos descritos manifiestan una actualidad de convivencia topológica que no asegura integración en lo cualitativo.

Rumbo hacia la zona nororiente, la trayectoria continúa por las calles Renato Rocca y Capitán Ávalos, ambas urbanizadas durante la década de 1980 con el concurso de rellenos de suelo y la posterior instalación de viviendas sociales. Lo primero que se recoge en la voz de sus habitantes respecto de esta área es que está inmersa en un histórico conflicto ambiental, debido al acopio de deshechos de plomo. Esta zona carece de equipamiento público pero posee almacenes barriales, venta de comida y talleres mecánicos.

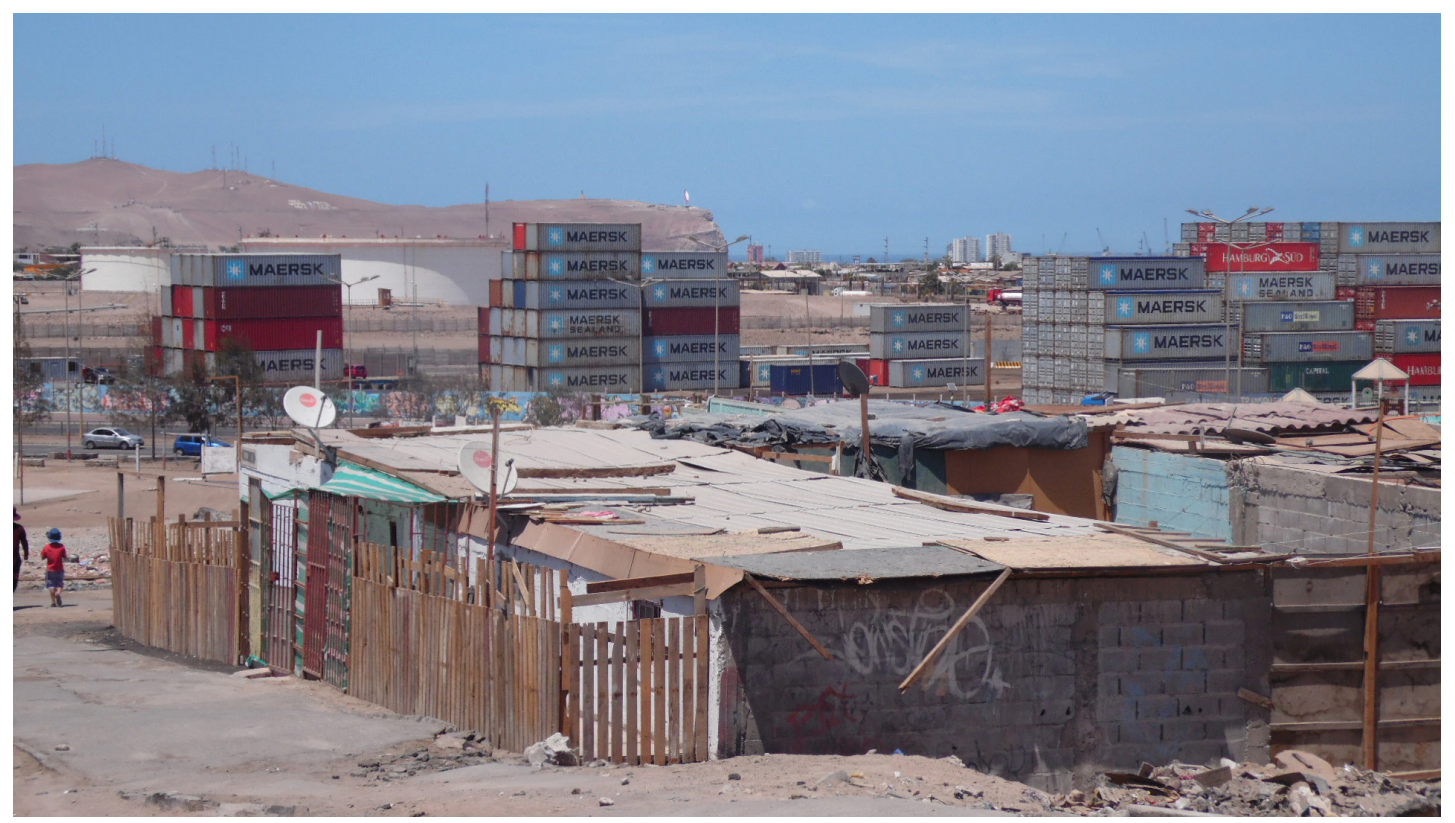

Figura 4. Cerro Chuño, Arica Norte.

Fuente: elaboración propia. 
En el ascenso hacia Cerro Chuño, población emblemática respecto del conflicto ambiental, se aprecia el opuesto significante del bienestar neoliberal ilustrado anteriormente. El barrio es una isla dentro de un área predominantemente industrial (Figura 5). Las viviendas edificadas sobre depósitos de residuos de procesos mineros, particularmente de polimetales, permanecen en el paisaje. El relato de los paseantes devela que las reubicaciones de población se sucedieron en tiempos recientes, aprovechando las redes urbanas ya instaladas en conjuntos residenciales próximos. Sin embargo, la nueva situación crítica se detona con tomas de terreno en el sector de los polimetales. En la actualidad convive población migrante, principalmente argentina, boliviana, peruana, colombiana y venezolana junto con familias chilenas. Se nos plantea que Cerro Chuño "es zona de nadie", horadando las iniciativas políticas de integración.

Si bien existen estigmas respecto del lugar y quienes lo habitan, produciendo una identidad deteriorada, no se reconocen mecanismos de cohesión y participación social de base, aplicándose categorías más cercanas al antigueto en el sector, basado en la no consolidación de prácticas colaborativas y de asociatividad comunitaria (Wacquant 2010).
Esto último deviene de las condiciones de sitio observadas. A la carencia de servicios urbanos y equipamiento básico, se imponen otros objetos urbanos que contribuyen al significado de barrio y cohesión, como iglesias, talleres, canchas de fútbol de tierra y cemento. No hay agua potable pero sí un camión dedicado a la venta de bidones con el recurso. Este servicio, junto con el camión aljibe proporcionado por el gobierno local son las únicas fuentes disponibles de agua. El paisaje de Cerro Chuño es el paisaje del detrimento urbano. Al costado de las calles se acumula basura y se respira aire denso producto de los aerosoles liberados por la quema de residuos domiciliarios, ante la escasa efectividad en la recolección de desechos.

Avanzado el transecto se advierten otros conjuntos residenciales precarios en su conservación. La ruta conduce al corral municipal de automóviles y, más arriba, al vertedero municipal, lo que condensa un paisaje de sacrificio. El transporte público no ingresa a Cerro Chuño, al que se llega solo por taxi-colectivos que arriban al pie del cerro.

En rumbo descendente, ingresamos a la población Los Laureles, asociada a las erradicaciones del sector de los polimetales. El paisaje olfativo del sector mezcla basura quemada y petróleo. A diferencia de Cerro Chuño, este barrio tiene

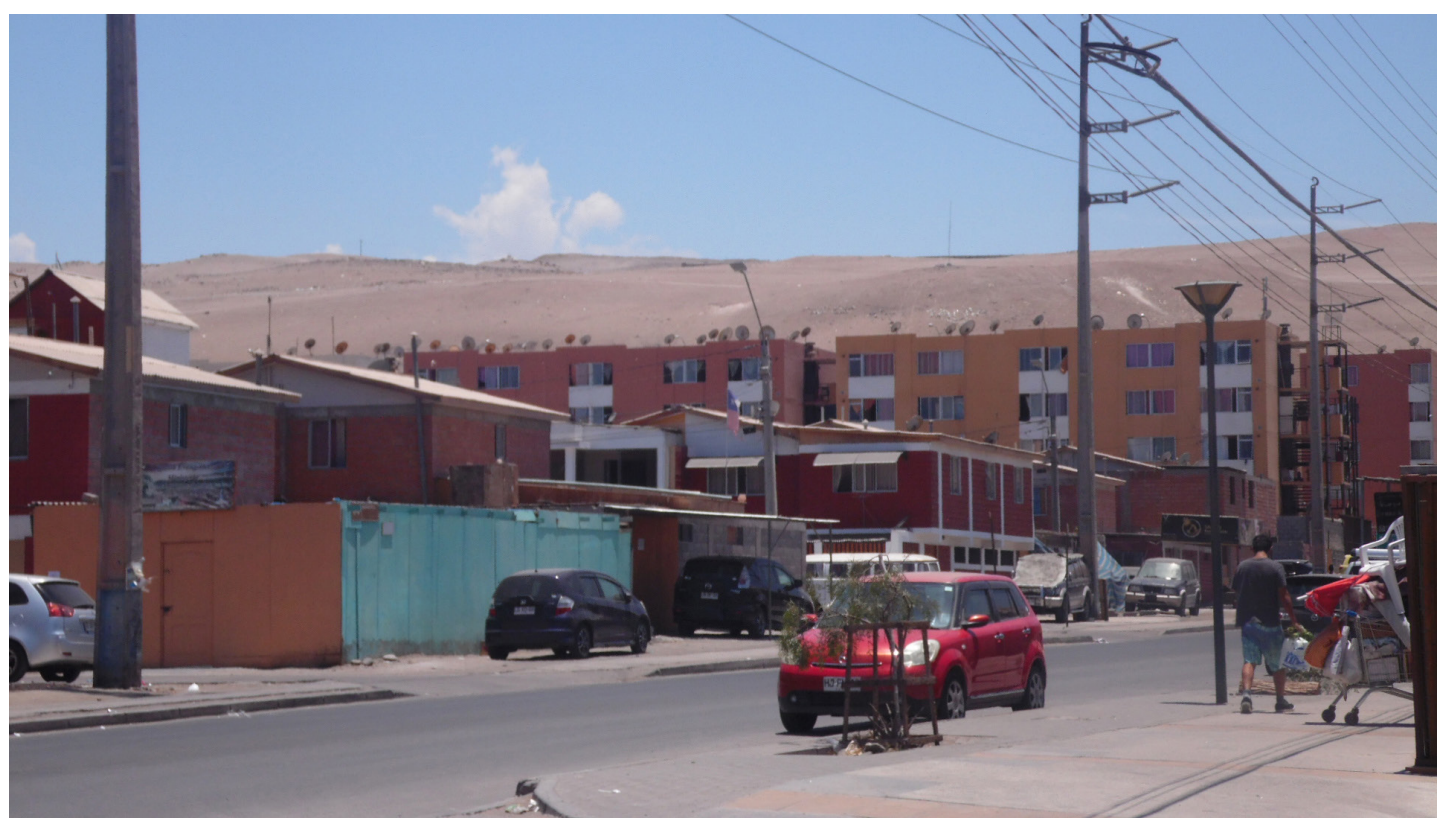

Figura 5. Los Industriales, Arica Norte.

Fuente: Elaboración propia.. 


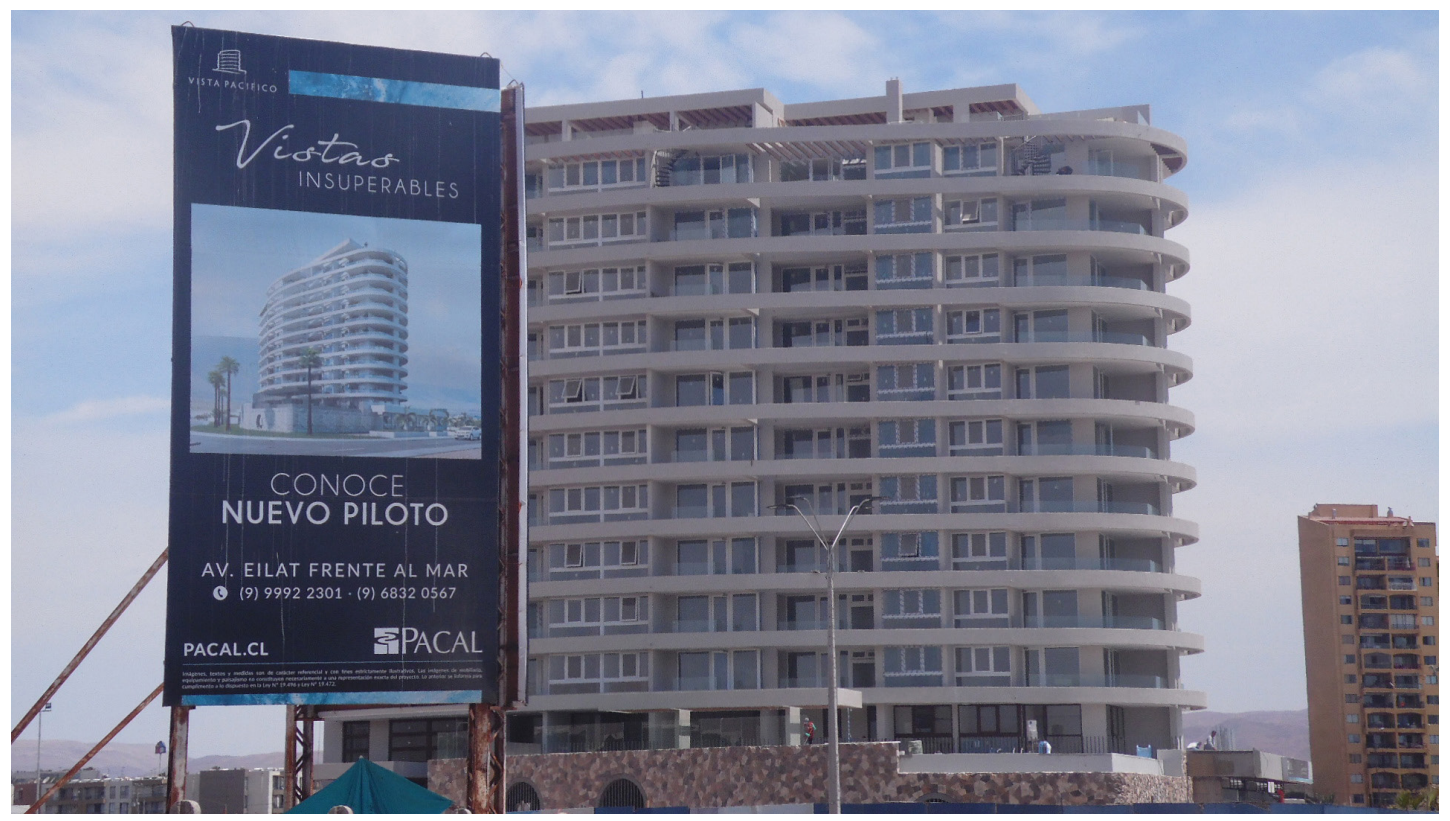

Figura 6. Urbanización en línea de costa, Arica Norte.

Fuente: Elaboración propia.

más comercio: hay casas donde se vende chatarra, almacenes y una pequeña feria que se da en medio de los pasajes. Es una pequeña centralidad barrial articulada a base del comercio informal de la vecindad.

La población Los Industriales aparece al norte. Este conjunto subsidiado de viviendas se edificó a inicios de los años noventa. La tipología habitacional predominante es la casa pareada, aunque se advierte la construcción de nuevos departamentos asociados a subsidios habitacionales por parte de la Inmobiliaria PACAL. Se diferencia de los anteriores por la consolidación de los entornos residenciales respecto del espacio público. Con la desaparición de basura en las veredas, el paisaje se aleja de la idea de sacrificio. Un proceso de renovación urbana se presenta como excepción modernizadora en la ampliación de las residencias a partir de los subsidios provistos por el Programa de Protección al Patrimonio Familiar (DS 255) (Figura 6).

El volumen del equipamiento en el barrio es notoriamente mayor en comercio (comida rápida, restaurantes de barrio), servicios (talleres de automóviles), bienes de uso público (sedes sociales, canchas, bibliotecas, Centros de Salud Familiar-CESFAM), seguridad (Comisaría), deportes (gimnasios), iglesias (pentecostales y católicas), y colegios (públicos y fundaciones, anteriormente particulares subvencionados). La calle Cantera organiza la centralidad del barrio. En ella se concentran los flujos de personas durante la mañana y media tarde, debido a que hay un pequeño mercado de abastos y, alrededor de él, una feria libre.

Próximo a Los Industriales se encuentran El Olivar y los conjuntos Santa Clara 1 y 2, todos proyectos de vivienda subsidiada derivados de las erradicaciones de Cerro Chuño. Hacia el norte están las poblaciones de vivienda subsidiada Chinchorro 1, 2 y 3 , donde predominan las casas de ladrillo pareadas. En los paños disponibles aledaños se han instalado edificios que promocionan los recientes subsidios de integración social y territorial, como Altos del Sol y Altos del Mar. La centralidad está organizada por la intersección de las calles Linderos Oriente con Los Andes, cuyo bandejón central opera como espacio público. Rodeando a esta zona hay comercio (almacenes, talleres mecánicos y comida al paso), además de una sucursal del Banco Estado, centros de salud, establecimientos escolares y jardines infantiles de administración pública y privada en régimen subvencionado.

Desde la carretera Panamericana hacia la línea de costa por el norte se encuentran densos condominios cerrados, algunos emplazados sobre 


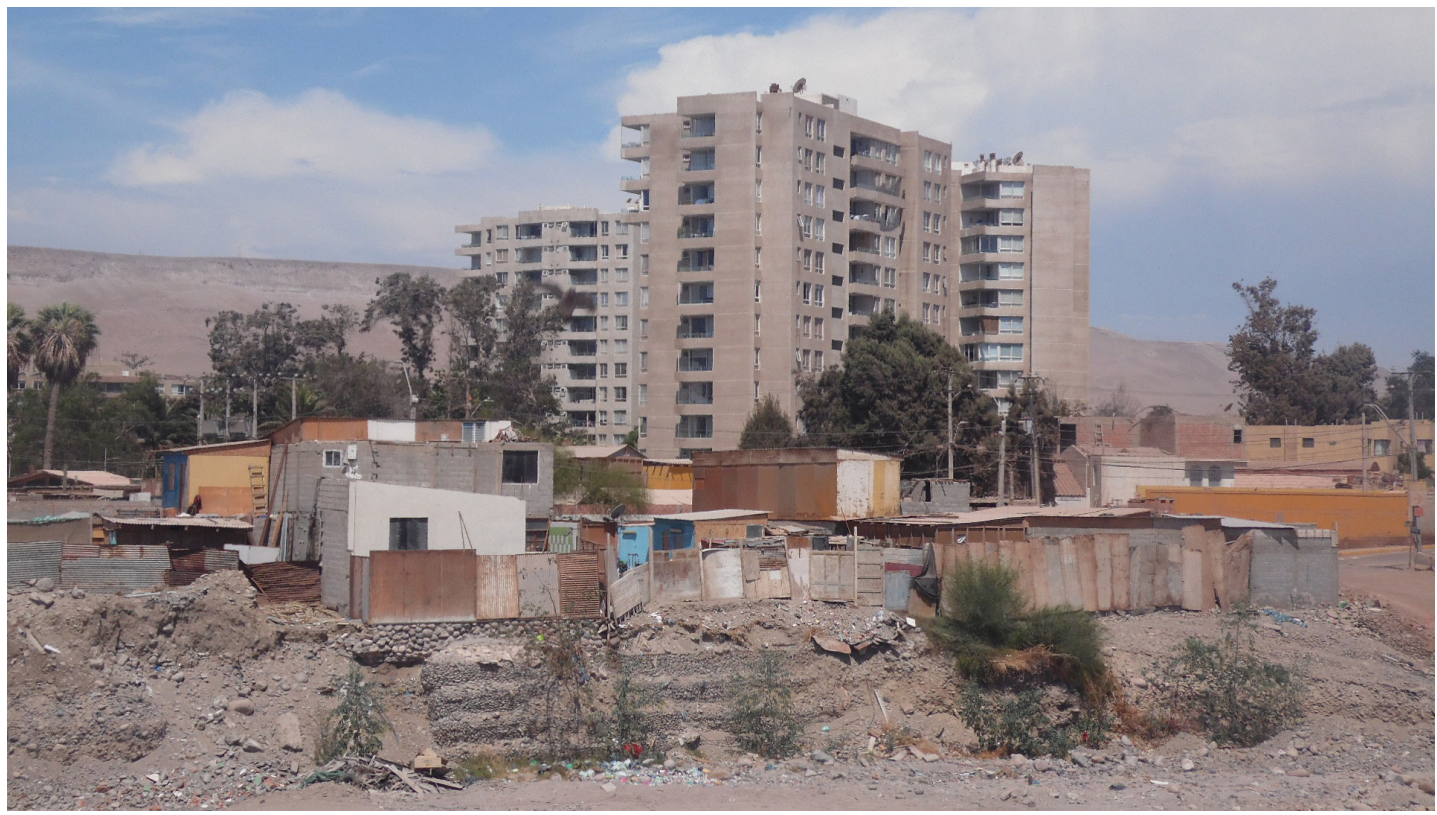

Figura 7. El Pedregal, Arica Centro-Sur.

Fuente: Elaboración propia.

rellenos de humedales próximos al mar. La recolección de información indica la existencia de un conflicto respecto de la preservación del humedal, ya que las organizaciones sociales prevén alzas en los proyectos residenciales del mismo tipo. La revisión del Plan Regulador Comunal de la ciudad $^{1}$ muestra una zonificación del tipo área residencial (ZR3-B) salvo un pequeño polígono decretado como área verde (AV) asociado solo a una parte de la totalidad del humedal.

Acá ingresamos a la zona denominada Gallinazo, proyectada hace cuatro décadas como espacio para el desarrollo de la ganadería. Actualmente se desarrollan conjuntos habitacionales subsidiados del Programa de Integración Social y Territorial. Estos proyectos son contiguos al humedal Lluta y cuentan con vistas a la costa. De Gallinazo hacia Chacalluta hay zonas de camping y más hacia el norte un reducido polígono industrial donde se encuentra Cementos Biobío y Villa La Frontera, sector habitacional caracterizado por tomas de terreno, parcelas, áreas de camping y los conjuntos cerrados de Alta Vista y Pedro Lagos. Se identifican microfronteras en este barrio, accesible solo mediante transporte particular. La construcción no cesa sobre el humedal, donde asoman pilotes que anuncian su relleno.

\section{Arica Sur}

El recorrido hacia la zona sur de Arica comienza por San Miguel de Azapa en el suroriente, por la Avenida Diego Portales, que conecta la suburbanización con el centro de la ciudad. Rumbo a Azapa se encuentra la Villa España, próxima al terminal agrícola Asocapec, urbanización subsidiaria de viviendas aisladas. A pesar de la vecindad a comercios, estadios deportivos y la Universidad de Tarapacá, se trata de un barrio aislado en que prima un paisaje definido por el río San José, con calles de tierra lejanas a la trama urbana consolidada. El relato de quienes transitan este sector señala la erradicación de tomas de terreno correspondientes a la Población El Buitre, inmediata a terrenos militares emplazados en Arica Sur.

En la ribera del San José se anuncia la construcción de nuevas viviendas subsidiadas. Siguiendo el trayecto hacia Azapa se localizan nuevas tomas de terreno, principalmente en la calle Remolino, siguiendo la línea del río. Al ingresar a Azapa se aprecian parcelas de agrado con gran cantidad de automóviles estacionados dentro y fuera de las residencias, denotando una función suburbana.

En esta zona predominan los usos residenciales, con algunos restaurantes de interés turístico y 


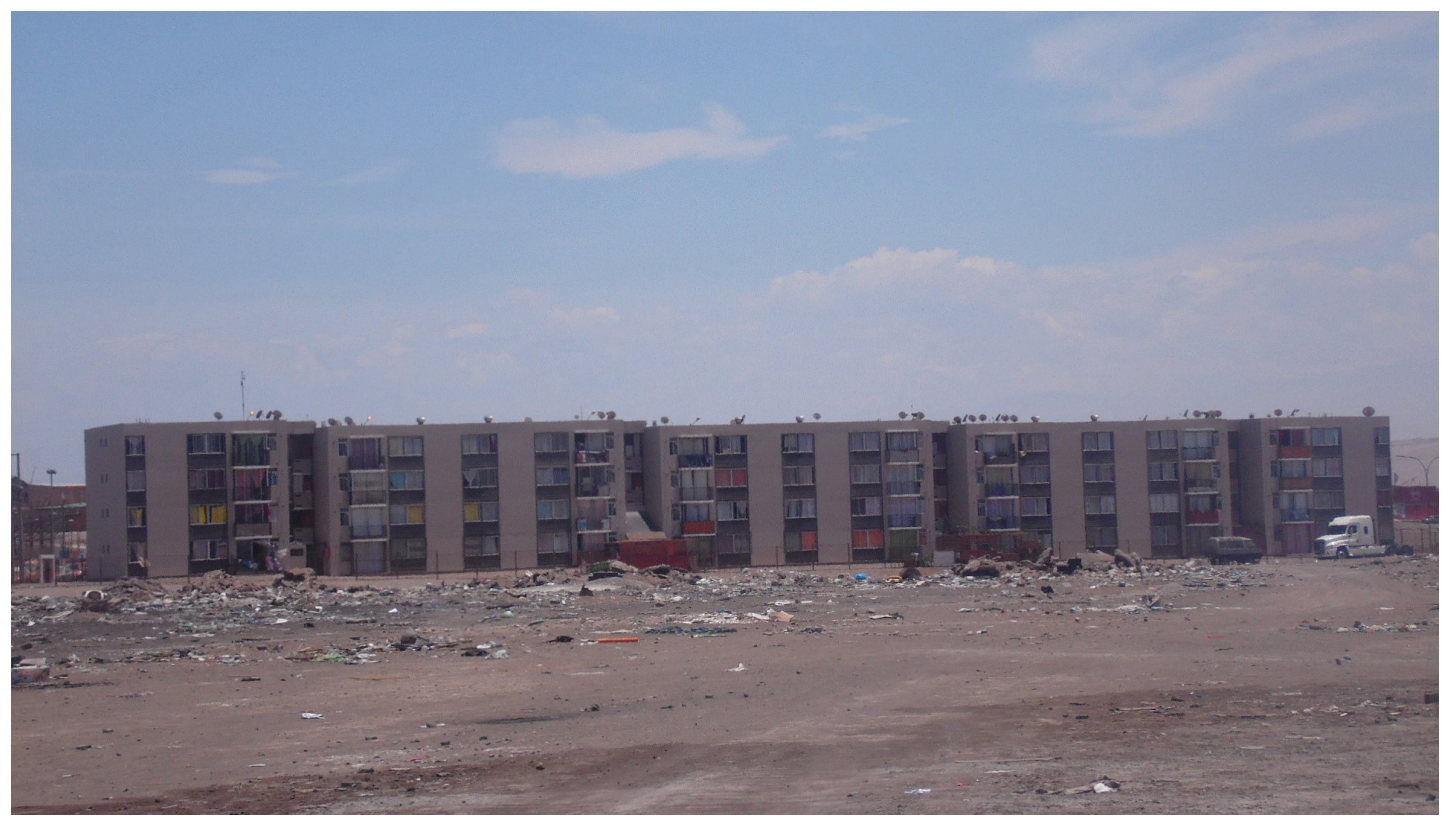

Figura 8. Población Miramar, Arica Sur.

Fuente: Elaboración propia.

escaso comercio minorista, cuestión que acrecienta la dependencia respecto del Arica consolidado. $\mathrm{Al}$ paso, quienes transitan por este sector indican que entre marzo y diciembre el flujo vehicular entre San Miguel de Azapa y Arica es de gran volumen, siendo la zona de mayor congestión vehicular de la ciudad.

La zona sur, siguiendo el camino costero, se distingue por el Alto de Arica. Se aprecia la construcción de nuevas residencias, más exclusivas, destacándose casonas aisladas y condominios verticales, como la torre Ayllú, cuyos valores iniciales son de $3.000 \mathrm{UF}^{2}$. En el camino que rodea las playas de la ciudad no hay mayores equipamientos, salvo algunos restaurantes y hoteles. Más al sur está el núcleo industrial pesquero.

Camino hacia las Cuevas de Anzota se encuentran grupos de personas acampando en la playa, lo que llama la atención por la cantidad de baños químicos disponibles. Quienes los ocupan señalan que esta constituye una práctica usual en las familias ariqueñas, donde resulta recurrente habitar la playa por una o dos semanas, mientras las casas se arriendan a veraneantes.

Detrás del Morro de Arica, se accede a la población Miramar, donde se observan tomas de terreno y nuevas urbanizaciones. Sobre los sitios eriazos de propiedad estatal copados de basura, se anuncian construcciones futuras en medio de las fundaciones de otras anteriores, inconclusas, como una residencia dependiente del Servicio Nacional del Adulto Mayor (Senama). Esta población carece de equipamientos y servicios, salvo el comercio barrial emplazado en algunas casas particulares. Todas las urbanizaciones existentes son producto de las políticas de vivienda subsidiada desde principios de 1990 a la actualidad. Resulta distintivo que la nueva vivienda subsidiada corresponde a tipologías de condominios cerrados, con estéticas opuestas al concepto de conjunto social predominante durante el pasado siglo, muy similares a los condominios de clase media existentes, por ejemplo, en la línea de costa de la zona norte.

El recorrido continúa por la calle Rafael Sotomayor hacia el sur, donde se encuentra la población El Buitre, una de las más emblemáticas de esta zona asociada, además, a un conflicto ambiental. Una parte de esta población debió erradicarse debido a la baja aptitud del suelo para edificaciones de gran escala, lo que produjo socavones en la superficie producto de filtraciones de agua.

Las nuevas urbanizaciones subsidiadas están equipadas con paneles solares. Casi no hay plazas públicas, pero sí espacios comunes dentro de los nuevos barrios cerrados. Resulta llamativo que 
estos condominios posean más estacionamientos que equipamiento o áreas de esparcimiento. Las calles Rafael Sotomayor y San Ignacio Loyola articulan a estos barrios. Es en torno a ellas donde se concentra la localización de escuelas públicas, jardines infantiles, comercio barrial de comida rápida, licorerías y almacenes que colindan a iglesias y clubes deportivos.

\section{A modo de conclusión: ¿precariópolis estatal ariqueña o la insostenible integración social urbana de la vivienda subsidiada?}

La integración social urbana en la producción de vivienda subsidiada en la ciudad de Arica resulta conflictiva. En los datos expuestos se aprecia una amplia brecha entre los efectos perseguidos por los programas gubernamentales hace más de veinte años, y su materialización en el espacio urbano producido.

Por ejemplo, la accesibilidad al equipamiento urbano básico es deficitaria. El incumplimiento de estándares propuestos por el Consejo Nacional de Desarrollo Urbano (Figuras 2 y 3 ) se acusa en las zonas norte y sur, altamente pobladas, que no cuentan con centros de salud a una distancia considerable, a diferencia de las áreas centrales, altamente equipadas (con tres centros de salud, oferta privada y un hospital público) pero mucho menos densas en población. Asimismo, los indicadores de segregación residencial describen una ciudad que lentamente pierde zonas de integración social, cuestión que se suma al establecimiento de estigmas en barrios como Cerro Chuño. La síntesis de estos resultados ofrece la siguiente sistematización:

1) El centro histórico y la ciudad construida por la Junta de Adelanto de Arica concentran la centralidad urbana. La oferta educativa, sanitaria, comercial y de ocio tiende a aglomerarse dentro de los límites del espacio urbano creado por modalidades desarrollistas.

2) La producción de vivienda subsidiada en las zonas norte y sur posee características de precariópolis: bajo acceso a equipamiento urbano; zonas predominantemente monofuncionales; distancia espacial con la ciudad consolidada; y los efectos fragmentadores de las carreteras sobre la trama urbana, generando una mayor condición de aislamiento.

3) La producción de vivienda en la línea de costa se basa en la promoción del paisaje costero con vista al mar, aprovechando las amenidades existentes (Hidalgo et al. 2016). La lógica de producción de naturaleza opera dentro de la oferta inmobiliaria de manera distintiva: en la costa sur responde a proyectos de un carácter mucho más exclusivo, mientras que en la costa norte es posible acceder mediante vivienda subsidiada para la clase media.

En definitiva, el estudio de la localización de la vivienda subsidiada en Arica responde a las lógicas con las que el Estado chileno produce espacio habitacional (Hidalgo et al. 2016). Su paisaje y sus condiciones urbanas son los de una precariópolis (Hidalgo, 2018), emplazada en las periferias norte y sur, presentando características de relegación social en tanto carencia de equipamiento público y baja accesibilidad a estos, impidiendo resolver los conflictos ambientales vigentes desde hace más de treinta años.

La densificación periférica, el aislamiento y el aumento de construcción de vivienda bajo la tipología de barrio cerrado dan cuenta de un modo distinto de producción estatal de vivienda en Chile (Hidalgo, 2005; 2018; Sugranyes 2005). La mezcla social como utopía liberal parece no encontrar lugares de expresión en tanto la lógica con la que opera el subsidio a la demanda favorece la estratificación social (Stiglitz, 1997), cuestión que significa que la distribución espacial de las clases sociales que acceden a programas de vivienda inevitablemente tiende a homogeneizarse.

La búsqueda de equilibrar un aumento del estándar de la calidad de la vivienda en conjunto con la apertura de un nicho de renta que sea atractivo para la inversión inmobiliaria encuentra su lugar en la política pública (Sabatini y Brain, 2008). En ella, la retórica de la integración y la sostenibilidad no permite apreciar con claridad la inversión de sí misma: zonas predominantemente monofuncionales, barrios más bien socialmente homogéneos, aislados del centro de la ciudad y asociados a riesgos ambientales. Entonces, la real función no parece ser el mejoramiento integral de la calidad de vida de las clases populares, sino que otorgar un mayor dinamismo al mercado de suelo para que las empresas inmobiliarias puedan extraer altas cantidades de renta bajo el lema de construir más y mejor ciudad para todos. Los significados en tensión asoman antes que otras razones. 


\section{Referencias Citadas}

Alvarado, V.

2019 "El bienestar en el Estado Neoliberal: escenarios de la propiedad en el Gran Santiago". Revista Cultura-HombreSociedad 29 (2):13-35.

Arriagada, C. y N. Morales

2006 "Ciudad y seguridad ciudadana en Chile: revisión del rol de la segregación sobre la exposición al delito en grandes urbes". Revista Eure 32 (97):37-48.

Bustos, R.

2005 "Desarrollo local y representación: el concepto de crisis". Revista Diálogo Andino 25: 53-76.

Cáceres, G. y F. Sabatini

2007 "Suburbanización y segregación urbana en el Chile decimonónico: hipótesis sobre la formación histórica del Gran Valparaíso". En Historias urbanas: homenaje a Armando de Ramón, editado por J. Valenzuela, pp. 93-122. Ediciones Universidad Católica de Chile, Santiago de Chile.

Calderón, R.

2014 "Por allá nací y allá me crié. Identidad y memoria de los últimos habitantes de la pampa salitrera de Tarapacá. 1930-1979. El caso de los pampinos de Arica". Revista Diálogo Andino, 45: 51-61.

Cavieres, E y Chávez, P.

2014 “ ¿Neomalthusianismo o falta de desarrollo social? A propósito de la población y oportunidades en Arica en las últimas décadas". Revista Diálogo Andino, 45: 119-129.

Censo de Población y Vivienda

1982 Instituto Nacional de Estadísticas [INE]. Santiago de Chile.

Censo de Población y Vivienda

1992 Instituto Nacional de Estadísticas [INE]. Santiago de Chile.

Censo de Población y Vivienda

2002 Instituto Nacional de Estadísticas [INE]. Santiago de Chile.

Censo de Población y Vivienda

2017 Instituto Nacional de Estadísticas [INE]. Santiago de Chile, http://www.censo2017.cl (Diciembre, 2019)

Díaz, A., L. Galdames y R. Ruz

2014 Tiempos violentos. Fragmentos de Historia Social en Arica. Ediciones Universidad de Tarapacá, Arica.

Fuster, X.

2019 "Las políticas de vivienda social en Chile en un contexto de neoliberalismo híbrido". Revista Eure 45 (135): 5-26.

Galasso, E.

2011 "Alleviating extreme poverty in Chile: the short term effects of Chile Solidario". Estudios de Economía 38 (1): 101-127.

Galeno, C.

2013 Arica, la Junta de Adelanto y las convergencias del Brutalismo. X Seminario Docomomo Brasil Arquitectura Moderna e Internacional Curitiba. Conexiones Brutalistas 1955-75, Curitiba.

Galdames, L. y R. Ruz

2010 "La Junta de Adelanto de Arica y Jhon V. Murra. Dos lecturas sobre el desarrollo andino en el norte de Chile". Revista Chungará 41 (1): 257-270.
González, D.

2018 "Chilenizando el Habitar. Cambios e incorporaciones en el habitar domestico de los aymaras urbanos en la ciudad de Arica". Revista Dialogo Andino 55: 121-130.

González, D. y H. González

2019 "La migración de la vivienda aymara y el crecimiento de la ciudad de Arica entre 1950 y 1990". Revista Interciencia 44 (12): 676-680.

Haramoto, E., P. Chian, R. Sepulveda e I. Kliwadenko 1987 Vivienda Social: Tipología de desarrollo progresivo. Editorial Instituto de la Vivienda, Santiago de Chile.

Hidalgo, R.

2018 "La dispersión de la vivienda social en gran escala en la periferia metropolitana de Santiago de Chile. La precariópolis y el derecho a la ciudad". En Pobreza urbana, vivienda y segregación residencial en América Latina, compilado por D. Soldano, A. Novick, M. Cravino y M. Barsky, pp. 111128. Ediciones UNGS, Buenos Aires.

Hidalgo, R.

2005 La vivienda social en Chile y la construcción del espacio urbano en el Santiago del siglo XX. Centro de Investigaciones Diego Barros Arana, Santiago de Chile.

Hidalgo, R., V. Alvarado, V. P. Quijada y D. Santana

2017 "Estado y propiedad. La política de vivienda social y la construcción de rutas al neoliberalismo en América Latina y Chile". Revista de Ciencias Sociales 32: 11-33.

Hidalgo, R., A. Paulsen, y D. Santana

2016 "El neoliberalismo subsidiario y la búsqueda de justicia e igualdad en el acceso a la vivienda social: El caso de Santiago de Chile (1970-2015)". Andamios, 13 (32): 57-81.

Kaztman, R.

2001 "Seducidos y abandonados: el aislamiento social de los pobres urbanos". Revista CEPAL 75 :171-189.

Mayol, A.

2019 Big Bang. Estallido social 2019. Modelo derrumbado. Sociedad rota. Política Inútil. Editorial Catalonia, Santiago de Chile.

Ministerio de Vivienda y Urbanismo [MINVU]

1998 Mirando detrás de la Fachada. Tres Casos en Arica. Una vía de evaluación de la vivienda pública. SERVIU Región de Tarapacá, Provincia de Arica/Parinacota. Centro de Documentación, Santiago de Chile.

Ministerio de Vivienda y Urbanismo [MINVU]

2020 Observatorio urbano. MINVU, Santiago de Chile, https:// www.observatoriourbano.cl/estadisticas-habitacionales/ (Diciembre, 2019)

Navarrete, P. y F. Toro

2019 "Urban Systems of Accumulation: half a century of chilean neoliberal urban policies". Revista Antipode 51 (3): 889-926.

Ozler, S.

2012 "The Concertación and Homelessness in Chile: Marketbased Housing Policies and Limited Popular Participation". Latin American Perspectives 29 (4): 53-70.

Orellana, A., M. Díaz y M. Fierro

2016 "De ciudad mediterránea a metrópolis costera: el caso de Gran la Serena”. Urbano 19 (33): 30-43. 
Pellicer, I., P. Vivas y J. Rojas

2013 "La observación participante y la deriva: dos técnicas móviles para el análisis de la ciudad contemporánea. El caso de Barcelona". Revista Eure 39 (116): 119-139.

Pérez, L. y R. Hidalgo

2010 Concepción metropolitano: evolución y desafíos. Concepción: Editorial Universidad de Concepción y Serie GEOlibros, Concepción y Santiago de Chile.

Pizarro, E. y W. Ríos

2005 "Entre Franquicias y Beneficios: una apuesta del gobierno para el desarrollo regional de Arica (1953)". Dialogo Andino 25: 106-111.

Programa de Naciones Unidas para el Desarrollo [PNUD] y Ministerio de Vivienda y Urbanismo [MINVU]

2014 Política Nacional de Desarrollo Urbano. Ciudades sustentables y calidad de vida. Santiago, Chile. https://cndu. gob.cl/wp-content/uploads/2014/10/L4-Politica-NacionalUrbana.pdf.

Rodríguez, J. y C. Arriagada

2004 "Segregación residencial en la ciudad latinoamericana". Revista Eure 29 (89): 5-24.

Rodríguez, A. y P. Rodríguez

2013 Con subsidios, sin derecho. Ediciones Sur, Santiago de Chile.

Rojo, F., T. Jara y J. Frick

2019 "Las urbanizaciones cerradas en la ciudad intermedia. El caso de Temuco (Chile) 2005-2014". Bitácora Urbano Territorial 29 (1): 79-90.

Ruiz Tagle, J.

2016 "La segregación y la integración en la sociología urbana: revisión de enfoques y aproximaciones críticas para las políticas públicas". Revista INVI 31 (87): 9-57.

Ruiz-Tagle, J. y S. Romano

2019 "Mixtura Social e Integración urbana. Aproximaciones teóricas y discusión del caso chileno". Revista INVI 34 (95): 45-69.

Sabatini, F. e I. Brain

2008 "La segregación, los guetos y la integración social urbana: mitos y claves". Revista Eure 34 (103): 5-26.

Sabatini, F. y R. Salcedo

2007 "Gated communities and the poor in Santiago, Chile: Functional and symbolic integration in a context of aggressive capitalist colonization of lower-class areas". Housing policy 18 (3): 577-606.

Salcedo, R.

2010 "The last slum: moving from illegal settlements to subsidized home ownership in Chile". Urban Affairs Review 46 (1): 90-118.
Salinas, E. y L. Pérez

2011 "Procesos urbanos recientes en el Área Metropolitana de Concepción: transformaciones morfológicas y tipologías de ocupación”. Revista de Geografía Norte Grande 49: 79-97.

Sistema de Indicadores y Estándares del Desarrollo Urbano [SIEDU]

2017 Instituto Nacional de Estadísticas, Ministerio de Vivienda y Urbanismo, Consejo Nacional de Desarrollo Urbano y Programa Naciones Unidas para el Desarrollo, http://siedu. ine.cl/compromisos/compromisos.html (Enero, 2017).

Stiglitz, J.

1997 La economía del sector público. Antoni Bosch, Barcelona.

Sugranyes, A.

2005 "La política habitacional en Chile, 1980-2000: un éxito liberal para dar techo a los pobres". En Los con techo. Un desafío para la política de vivienda social, editado por A. Rodríguez y A. Sugranyes, pp. 23-58. Ediciones Sur, Santiago de Chile.

Tapia, R.

2011 "Vivienda social en Santiago de Chile. Análisis de su comportamiento locacional, período 1980-2002". Revista INVI 26 (73): 105-131.

Valdebenito, C.

2014 "La huella socioeconómica y demográfica en la estructura residencial de las ciudades medias de Latinoamérica: el caso de Viña del Mar-Chile en la década 1992-2002". Scripta Nova. Revista Electrónica de Geografía y Ciencias Sociales 18 (492).

Valdebenito, F. y K. Navarro

2019 "Transformación, reescalamiento y desigualdad urbana contemporánea en Arica: la toma de Cerro Chuño como caso de (in)justicia espacial". Rumbos TS XIV (19): 145-172.

Vergara-Constela, C.

2013 "Integración social en barrios vulnerables a través de procesos educativos no formales. El caso del Taller de Acción Comunitaria (TAC) del cerro Cordillera de Valparaíso". Bitácora Urbano-Territorial 22 (1): 163-175.

Vergara, L., R. Gola y V. Huiliñir

2015 "Los inicios de la insustentabilidad: problemas urbanos e institucionalidad en la ciudad de Temuco, 1955-1970". Cuadernos de vivienda y urbanismo 8 (16): 64-281.

Wacquant, L.

2010 Las dos caras de un gueto. Siglo XXI Editores, Buenos Aires.

\section{Notas}

1 En las siguientes referencias es posible apreciar tanto el plano como la ordenanza local asociado. Plano: https:// transparencia.municipalidaddearica.cl/uploads/file/ LEY20285/2015/ENERO/Plan_regulador/Plano_regulador_2009.pdf; Ordenanza: https://transparencia. municipalidaddearica.cl/uploads/file/LEY20285/2011/ ABRIL/7_Actos_y_Resoluciones/Varios/ORDENANZA_ PLAN_REGULADOR.pdf
2 La Unidad de Fomento (UF) es una unidad de cuenta reajustable con la que se adquieren distintos bienes y servicios, principalmente las viviendas y sus hipotecas. El valor convertido en dólares para mayo de 2020 corresponde a 35,94 USD (adaptado de Alvarado 2019). 